\title{
Older drivers' use of rear view camera systems: Examining technology adoption in the high-tech automobile
}

\author{
Ruheena Sangrar MScOT ${ }^{\mathrm{a}, *}$ \\ Alexandra S. Mueller PhD ${ }^{a}$ \\ Jessica Gish $\mathrm{PhD}^{\mathrm{b}}$ \\ Lauren Griffith $\mathrm{PhD}^{\mathrm{c}}$ \\ Lori Letts $\mathrm{PhD}^{\mathrm{a}}$ \\ Brenda Vrkljan $\mathrm{PhD}^{\mathrm{a}}$
}

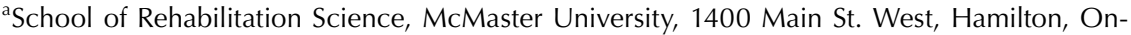
tario, Canada L8S 1C7; ${ }^{b}$ Gilbrea Centre for Studies in Aging, McMaster University, 1400 Main St. West, Hamilton, Ontario, Canada L8S 1C7; ' ${ }^{\circ}$ epartment of Health Research Methods, Evidence and Impact, McMaster University, 1400 Main St. West, Hamilton, Ontario, Canada L8S 1C7; *Corresponding author: sangrarr@mcmaster.ca
\end{abstract}

\begin{abstract}
R Sangrar, AS Mueller, J Gish, L Griffith, L Letts, B Vrkljan. Older drivers' use of rear view camera systems: Examining technology adoption in the high-tech automobile. Gerontechonology 2018;17(2):90-101 https://doi.org/10.4017/gt.2018.17.2.003.00 Background Advanced Driver Assistance Systems (ADAS) offer much potential to address age and health-related changes that can negatively impact driving in older adulthood. Rear view cameras (RVCs) are one example of ADAS-related technology that aims to enhance the performance of reversing manoeuvres by improving visibility behind one's vehicle. However, it is not yet clear how older drivers learn to use such technology. Objective The aim of this study was to explore older drivers' experiences and perceptions of learning to use RVCs, with a focus on how these technological advancements become part of their everyday driving. Method Interviews were conducted with 15 older drivers who had an RVC system in their primary vehicle. Interpretive description, a qualitative methodology, was used to examine their experiences with learning to use this technology. Findings Participants described a phased process of learning to use an RVC by first becoming acquainted with the technology and then testing its limits under various conditions. These findings demonstrate how older drivers engage in trust-building activities to understand the usability of this technology. Implications Awareness of these phases can inform training as well as the future design of ADAS that have the potential to improve the safety of older adults when behind-the-wheel.
\end{abstract}

Keywords: usability, advanced driver assistance systems, aging, older driver, learning, rear view camera

\section{INTRODUCTION}

In the United States alone, over 200 pedestrians are killed annually by drivers who are backing-up their vehicles'. Reversing or backing up a motor vehicle involves a complex series of manoeuvres which can be impacted by age and health-related changes ${ }^{2}$. Older drivers can perform reversing errors by failing to identify and respond appropriately to environmental factors, such as hitting an obstacle when reversing ${ }^{3}$ due to difficulties turning their head and body ${ }^{4}$. Given these challenges, recent advancements in automotive technologies, such as rear view cameras (RVC), show much potential for improving driving safety in older adulthood ${ }^{5,6}$.

On-road studies have found that RVCs can improve rear visibility ${ }^{7}$ and obstacle recognition by drivers, particularly when paired with auditory alerts $^{7-10}$. They have also been shown to reduce vehicle collision rates by $17 \%{ }^{11}$, and up to $62 \%$ when paired with vehicle assist systems ${ }^{12}$. As of 2018, all passenger vehicles manufactured in the United States and Canada that weigh less than 10,000 lbs will be required to have an $\mathrm{RVC}^{13,14}$. Among the first advanced driver assistance systems (ADAS) to be mandated, RVCs do not take 
over any aspect of the driving task. Their functionality places them at the first of six levels of automated driving systems ${ }^{15}$. These levels range from 'no automation' (Level 0), meaning the technology provides passive information to the driver who retains full operation of the vehicle, to 'full automation' (Level 5), where the technology controls all aspects of the driving task ${ }^{15}$. Understanding how older drivers adopt and learn to use technologies at lower levels can inform how they might adopt more sophisticated systems, including autonomous vehicles.

Studies have explored early use and acceptance of ADAS. For instance, Trösterer and colleagues ${ }^{16}$ tracked driver experiences with using parking assist systems in their new vehicles $(n=11$, mean age $=27.18$ years, $\mathrm{SD}=4.73$ ). In this repeatedmeasures study, the level of technology acceptance was found to fluctuate in the first few days of using the system ${ }^{16}$. This fluctuation was linked to participants' varied initial experiences with operating the technology ${ }^{16}$. Drivers' perceptions of RVCs over time have also been explored. Results from a survey of vehicle owners ( $n=1537$, median age $=51$ years) indicated their rate of using their RVC was much higher once they were accustomed to having access to this technology, as compared to when they first bought their vehicle $^{17}$. Of those surveyed, drivers aged 65 years and older were less likely to use their system and did not understand how the technology worked in fog, cold, and rainy conditions. They were also less likely to rate the technology as 'very easy' to use $^{17}$. Driver interactions with their RVCs have also been captured. An observational study of older drivers $(n=14$, mean age $=77, \mathrm{SD}=3.97)$ found that RVCs were commonly used in complex environments, including busy parking lots where other vehicles and pedestrians were present ${ }^{18}$. Participants described RVCs as an additional means of gathering information from their driving environment that augmented information from other sources (e.g., mirrors and shoulder checks) $^{18}$. Observational studies of older drivers are important for analyzing actual performance, but the process by which drivers learn to use RVCs has yet to be examined.

Studies exploring vehicle owners' early use of reversing technologies suggest formal training on how to use their systems at the time of vehicle purchase is limited $^{16-18}$. Online versions of ADASrelated training resources have been accessed by $1 \%$ of vehicle owners in $2008^{17}$ and $16 \%$ of vehicle owners in $2015^{19}$. Internet-based training was found to be among the least accessed educational resources by older drivers with reversing systems ${ }^{20}$. For older adults, the most popular sources of knowledge for learning to use vehicle technology have been through self-instruction or instruc- tion from dealerships ${ }^{17,19,20}$. However, Abraham, McAnulty, Mehler, and Reimer ${ }^{21}$ suggest salespeople from major automotive dealerships may be providing inaccurate information about the functionality and limitations of $\mathrm{ADAS}^{21}$. Drivers may not be learning how to use the technology as intended by vehicle manufacturers thus mitigating their capacity to prevent collisions ${ }^{12}$. There is a lack of evidence with regard to appropriate approaches that can be used to educate older adults who purchase vehicles with $\mathrm{ADAS}^{5}$.

Educational strategies are often informed by theoretical models that explain behaviour. Use of theoretical models derived or adapted to explain the use of technologies can inform an understanding of older adults' experiences with learning to use RVC. Identifying barriers and facilitators for this population is important to determine the best strategies to promote safe and appropriate use of such technologies. A frequently investigated construct is user acceptance of technology, often referred to as behavioural inten$\operatorname{tion}^{22,23}$. For example, the Unified Theory of Acceptance and Use of Technology ${ }^{23}$ (UTAUT) has been adapted to understand driver acceptance of ADAS. This theory informed the development of the Car Technology Acceptance Model ${ }^{22}$ (CTAM). The CTAM specifically describes key constructs that can promote a driver's intention to use ADAS. This model illustrates how use and acceptance of ADAS results from the confluence of many factors, including a driver's perception of how the technology works (i.e., performance expectancy), ease of use (i.e., effort expectancy), the opinion of others (i.e., social influence), and availability of support and resources (i.e., facilitating conditions $)^{22}$. These factors are important to consider when it comes to understanding the adoption rates of ADAS among older drivers, given their extensive driving history, range of comfort with using various types of technologies, as well as health and age-related changes that can impact their behind-the-wheel behaviour ${ }^{24}$. Table 1 outlines key constructs of the CTAM in relation to use of RVCs among older drivers.

To date, studies using UTAUT or CTAM have been deductive in terms of their research design (e.g., surveys). Studies that provide fixed response options cannot explore variations within and across user experiences of learning to use such technology. Investigators have combined surveys with other forms of data collection to triangulate findings from multiple sources. For example, an online survey of drivers who had never used fatigue monitoring or adaptive cruise control systems $(\mathrm{n}=387$, mean age $=35.6, \mathrm{SD}=11$ ) was followed by inviting them to use these technologies in a driving simulator ${ }^{25}$. Simulator performance augmented the survey findings to inform theory development on users' technol- 
Table 1. Descriptions of the constructs of the Car Technology Acceptance Model2 (CTAM) and examples of how these constructs apply to using a Rear View Camera (RVC)

\begin{tabular}{ll}
\hline Constructs of the CTAM Examples of the CTAM applied to an older driver's use of RVC \\
\hline
\end{tabular}

\section{Performance Expectancy}

A driver's perception of the degree to which using ADAS The older driver perceives using an RVC will make reversing will enhance the performance of driving behaviour. and parking more efficient and precise.

\section{Effort Expectancy}

A driver's perception of how easy it is to use the ADAS. The older driver perceives the RVC system easy to interpret and to use while reversing and parking.

\section{Social Influence}

A driver's perception of whether other important individuals believe he/she should use ADAS.
Friends and family of the older driver have talked about how useful the RVC is and encouraged him/her to use it.

\section{Facilitating Conditions}

A driver's perception of the resources that exist to help him/her use various ADAS systems.

The older driver knows they can read the manual or ask the sales representative at the dealership how to use the RVC.

\section{Anxiety}

The degree of apprehension or uneasiness a driver

An older driver feels nervous or unsure when using the RVC experiences in situations when he/she uses his/her ADAS. and needs to double-check what they see in the RVC is truly in the road environment.

\section{Self-Efficacy}

A driver's perceived ability and competence using ADAS The older driver feels that they are using the RVC correctly and and safely perform driving behaviours. in the way, it is supposed to be used. Using the technology improves their ability to park and reverse.

\section{Perceived Safety}

A driver's perception that use of the ADAS will affect his/her well-being.

The older driver perceives that using the RVC will keep them safer and help them to avoid collisions.

\section{Attitude Towards Using Technology}

An overall affective reaction by the driver towards using In general, the older driver likes the concept of an RVC and has ADAS.

a positive opinion about using it.

\section{Behavioural Intention}

A driver's intention to use ADAS, demonstrating technology acceptance.

The older driver intends to use the RVC.

\section{Use Behaviour}

A driver's actual use of ADAS.

The older driver's use of an RVC in everyday driving.

Adapted from Osswald, Wurhofer, Trösterer, Beck, \& Tscheligi ${ }^{22}$

ogy acceptance ${ }^{25}$. A survey on users' experiences with new parking assistance systems that collected data over time using Likert-scale response options also included free-text questions. Though such mixed-method approaches have allowed for multidimensional descriptions of drivers' experiences, participants' rationale for their responses requires qualitative exploration. Understanding the initial experiences of using this technology is critical to inform those who design vehicles and/or the training associated with these systems ${ }^{5,26}$. However, the process by which older adults learn to use these technologies and incorporate them into their everyday driving is not well understood.

The purpose of this study was to explore how older drivers learn to use RVCs. The goal of this study was to characterize the process by which older adults learn to use this type of technology. The Car Technology Acceptance Model $(\text { CTAM })^{22}$ was used as a framework to understand the factors that can influence the experience of older drivers with learning to use an RVC, which sets the stage for understanding how technology adoption occurs in the automobile context. This study addressed the following research questions: (1) What are older adults' perspectives of learning to use ADAS, specifically RVCs, in their own vehicle?; (2) What factors influence their adoption of this technology?; and, (3) What are older drivers' perceptions of how their use of this technology has changed since purchase of their vehicles?

\section{Methods \\ Participants and Recruitment}

Sixty participants who consented to be contacted for research projects specific to older drivers were invited to participate in the research study. These individuals had been originally recruited through public advertisements and university databases. Prospective participants were reached by telephone where the study purpose and re- 
Table 2. Selected questions for participants from the semi-structured interview guide

\section{No. Examples of questions from the interview guide}

$1 \quad$ Please describe the key features of the rear view camera technology in your car.

2 How did you first learn about and how to use the reversing/parking assistive technology in your car?

3 How do you feel about the design of this technology? And how do you feel when you use it?

4 To what extent do you feel that backup cameras and other parking assist technologies [if applicable] are changing your habits/ routines?

5 To what extent does the backup camera work in the way that you expected? Were there any surprises?

quirements of participation were explained. To be eligible, participants were required to be: aged 65 years or older, have a valid driver's license, own a vehicle with an RVC, be medically cleared to drive, drive more than 4 days per week, and speak English fluently. Participants completed a brief demographic questionnaire about their vehicle ownership and vehicle characteristics. All participants received an honorarium for their participation. The Hamilton Integrated Research Ethics Board approved this study (\#1311).

\section{Procedure}

A semi-structured interview lasting 1 to 2 hours in length was conducted with each participant to examine older drivers' subjective experiences of learning to use an RVC in their own vehicles. Interviews were conducted in each participant's home between June and July 2016. Open-ended interview questions were designed to encourage participant reflection on how they learned to use their RVC and adopted this technology within their everyday driving habits and routines. Examples of questions are outlined in Table 2. Questions were adapted from fixed-response questions on quantitative instruments that use constructs of interest (e.g. trust and confidence in technology use) and constructs from the CTAM (e.g. effort expectancy, social influence, etc. $)^{22}$. All interviews were audio recorded and transcribed verbatim. Pseudonyms were used to maintain participant confidentiality.

Table 3. Selection of codes used in the analysis

\begin{tabular}{|c|c|}
\hline Select code & Description \\
\hline Parking situation & $\begin{array}{l}\text { Environments in which a reversing task might } \\
\text { occur; type of RVC used }\end{array}$ \\
\hline Trust & $\begin{array}{l}\text { Trusting the technology to provide accurate and } \\
\text { timely information }\end{array}$ \\
\hline $\begin{array}{l}\text { Improved efficiency/ } \\
\text { precision }\end{array}$ & $\begin{array}{l}\text { How the reversing maneuver is improved with } \\
\text { RVC use }\end{array}$ \\
\hline $\begin{array}{l}\text { Additive technology } \\
\text { use }\end{array}$ & $\begin{array}{l}\text { Combining information from various sources (i.e. } \\
\text { mirrors, proximity sensors, visual scanning, RVC) }\end{array}$ \\
\hline $\begin{array}{l}\text { Learning to use the } \\
\text { RVC }\end{array}$ & $\begin{array}{l}\text { Strategies and facilitators of learning how the RVC } \\
\text { works (e.g.: reading a manual, trial-and-error). }\end{array}$ \\
\hline Becomes automatic & Using the RVC does not take conscious effort \\
\hline
\end{tabular}

Analysis

Inductive thematic analysis ${ }^{27}$ of the interview data was undertaken to examine how participants described their adoption of this technology in their driving environment. A six-step process for thematic analysis, as described by Braune and Clarke ${ }^{27}$, was used to analyze interview transcripts, as follows:

(1) Investigators (RS \& JG) independently reviewed the transcribed data from three interviews to familiarize themselves with the data and identify emerging ideas;

(2) After their review, researchers met to discuss emerging ideas. Emerging codes, relevant literature on ADAS used by older drivers and the CTAM informed the development of a codebook. The codebook included preliminary codes as well as definitions of the codes and directions for how the code could be used. Table 3 presents a selection of codes identified in the codebook;

(3) Using this codebook, the first author (RS) systematically coded the transcripts using data management software (QSR International's NVivo 11 Software 2015). Next, these codes were consolidated into themes;

(4) The themes were reviewed to ensure they represented coded extracts from the interviews;

(5) Themes, codes, and their definitions were further refined based on identified relationships, as well as similarities and variations in participants perceptions of using the technology;

(6) Selected extracts for the manuscript were reviewed to ensure they adequately represented the themes. A peer auditor (BV) reviewed the process by which the final themes were determined and an agreement was confirmed between themes and the coding framework. Trustworthiness of the process was ensured through the use of verbatim transcription, iterative review of the coding framework, and an audit trail. The audit trail outlined the sequence of steps involved in the analysis alongside rationale for decisions made during analysis of the interview data. 


\section{Results}

Sixteen participants met the eligibility criteria and agreed to participate (Figure 1), with one participant later withdrawing. Sociodemographic characteristics are detailed in Table 4. Fifteen older drivers (10 males, 5 females) participated in the study. Their average age was 77.8 years $(\mathrm{SD}=4.2 ; \min =69$, $\max =84)$, and most participants had graduate degrees $(40 \%)$. Vehicle ownership ranged from 2 months to 3.5 years. Half of the sample $(53.3 \%)$ did not perceive any discomfort while driving; for those that did, stiffness in the neck was the most common condition (20\%).

Participants' vehicles were purchased after 2012. Two participants were a couple who drove the same vehicle. All participants had an RVC located in their vehicle's center console. A visual check by the researchers verified the location of this device. In addition to their RVC, many participants $(40 \%)$ had other ADAS in their vehicle, which included parking assist technologies. These ADAS are listed in Table 5.

Thematic analysis from the interviews indicated that older drivers in this study described how their initial impressions of the RVC system were influenced by how they were initially introduced to the ADAS and their early interactions with this technology. Identified themes describe a sequential process by which older drivers learned to use their RVCs within everyday driving routines. Key factors that shaped their interactions with the technology were described. Illustrative quotes are presented alongside each theme.

\section{Theme 1 'It's right there': Getting acquainted with the technology}

All participants were aware of RVCs before purchasing vehicles with this technology. For most participants, driving their vehicle off the dealership parking lot was their first opportunity to actually use the technology. When asked how they learned to use their respective system, most identified that their salesperson was instrumental in providing instructions. Daniel (age 81) recalled the experience of being oriented to information on his RVC when picking up his new vehicle at the dealership stating, "I was in the car and [the sales-

All participants within university databases interested in driving research were approached $(n=60)$ Participants not available (i.e.,
message left and no return phone call) $(n=19)$ or did not have RVCs $(n=20)$

Participants with RVCs screened for eligibility $(n=21)$

Participants that did not meet eligibility criteria $(n=3)$ or were not interested in participating $(n=2)$
Participants who met eligibility criteria $(n=16)$ manl had it in reverse and he showed me what the various lines meant lon the RVC display]." Other participants indicated they were oriented to the location of the RVCs on their vehicle, as Janet explained: "I know where the cameras are because they told us that, again the dealer said be careful if your car is covered in ice, because... it'll be expensive to replace this if you scrape it off with the scraper. So he showed me where the two cameras were." (Janet, age 74)

Participants also reported using instruction manuals as well as accessing videos about the technology on manufacturers' websites. Some indicated they learned how to use the technology by watching others, such as a spouse, use the system.

Participants also identified their ability to start using the system was closely linked to the physical design of the technology. Many used words such as "automatic", "easy", and "sensible" when 
Table 4. Sociodemographic characteristics of study sample $(n=15)$

\begin{tabular}{ll}
\hline Attribute & \\
\hline Age (years) $[$ mean $(S D ; \min , \max )]$ & $10(66.7)$ \\
\hline Gender [n $(\%)]$ & $59.9(6.2 ; 50,69)$ \\
Male & $1(6.7)$ \\
\hline Driving Experience (years) $[$ mean $(S D ; \min , \max )]$ & $4(26.7)$ \\
\hline Education Level $[\mathrm{n}(\%)]$ & $2(13.3)$ \\
Some high school & $2(13.3)$ \\
High school & $6(40.0)$ \\
College & \\
Undergraduate & $3(20.0)$ \\
Graduate & $2(13.3)$ \\
Perceived Discomfort while Driving $[\mathrm{n}(\%)]$ & $2(13.3)$ \\
Stiffness in the neck & $2(13.3)$ \\
Back pain & $2(13.3)$ \\
Knee pain & $2(13.3)$ \\
Weakness in the legs & $1(6.7)$ \\
Difficulty getting into the car & $1(6.7)$ \\
Difficulty getting out of the car & $8(53.3)$ \\
Difficulty hearing & $1.7(1.1 ; 0.17$, \\
Numbness in the fingers & $3.5)$ \\
None & \\
\hline Length of Vehicle Ownership (years) & \\
[mean (SD; min, max)] & \\
\hline
\end{tabular}

up 'experiments' to see how the systems actually worked when they were behind the wheel. Experimenting with the technology was perceived as a way not only to identify its capabilities but also to understand its limits. Such testing was usually done in a familiar context, such as a driveway. For example, Janet (age 74) described how she came to understand how her RVC worked with regard to judging distances to nearby obstacles behind the vehicle when reversing: "I told my husband to stand back there lbehind the carl and I could tell it is one car length behind so that gives me some distance". Harry (age 76) conducted a more formal experiment: "I took a piece of two by four out and laid it on the driveway, knowing where I put it, and then what the vehicle is showing, just what these lines are showing me distance-wise. So, it's a learning thing."

Initial experiences using the technology in everyday driving

reflecting on their initial impressions of the RVC. Scott indicated that he felt the RVC was integrated into his usual driving routine: "You just turn it on, you put your car in reverse and it's there... Oh, it's automatically there. What you're doing, it switches to that. And when you go back into drive it goes back into your music or whatever you're doing." (Scott, age 81)

Other participants felt they needed to supplemental verbal instructions or hands-on use with written material in order to better understand the capabilities of the technology in relation to its usability, as Joshua indicated: "[The salespeople] certainly talked about it, but I'm afraid when salespeople talk to me it goes in one ear and out the other... and reading the manual, because the manual did tell you... a bunch of things about what the significance of the lines [are]..." (Joshua, age 69)

The intuitive and integrated nature of the RVC facilitated how older drivers learned the functional characteristics of the system. However, instructional orientation to the technology was not sufficient to understand its entire functionality.

\section{Theme 2 'It took a couple of tries': Learning by doing}

Although the use of the technology felt intuitive, participants also described how they set were described as generally being positive. Judy described how following the guide lines on her RVC resulted in maintaining a safe space around her vehicle: "When I did use it for the one parking [I stopped] at the red line, I was surprised at how much space I still had between my car and the next one. So I thought "well that's a good guide as far as that goes." But there was quite a bit of space." (Judy, age 81)

Some participants also had negative experiences when initially using the technology, as Evelyn (age 72) described, "It took a couple of tries to work with the backup camera...because the first time I used a backup camera I hit the car behind me, so... [Participant laughter] Whoops." When participants felt more comfortable with using the technology they came to realize some of its drawbacks. For example, participants expressed concern that the viewing angle on the RVC display was limited.

Nigel emphasized that drivers still need to be aware of their surroundings when manoeuvring their vehicle, as the technology is not always capable of displaying potential hazards accurately: "There's just not enough coverage of left or right. [You know] it is there... if... that vehicle is creeping. But if it's moving at speed, not enough time. So you've got to verify you're clear to go, using both the mirrors and taking a quick look." (Nigel, age 81) 
Table 5. Participants' self-report of the types of additional advanced driver assistance systems within their vehicles

\begin{tabular}{lc}
\hline Vehicle Characteristic & $\begin{array}{c}\text { Number of } \\
\text { Participants }\end{array}$ \\
\hline Additional Park Assist Technologies $(n=6)$ & 6 \\
Proximity Sensors & 2 \\
Cross-Traffic Alert & 1 \\
Pedestrian Detection & \\
\hline Additional ADAS $(n=4)$ & 2 \\
Forward Collision Warning & 1 \\
Automated Braking & 2 \\
Lane Departure Warning & 3 \\
Blind-spot Detection & 2 \\
Adaptive Cruise Control & 1 \\
Navigation System & 1 \\
In-vehicle Communication System & \\
\hline
\end{tabular}

Concerns with relying on the technology too much were also realized in situations where the system's limitations contributed to a negative event: "I had to back up, and I actually backed up and scraped my bumper because there was brick behind us, a low level brick I didn't see. And it was dark and that camera was no use....[B]y and large they [RVCS] are beneficial, but an awful lot has to do with people's reaction to technology. If, in fact, you become too reliant on it, and for example, backing up, you forget about the sides of your car, then you got a problem." (Daniel, age 81)

Positive and negative experiences with using the RVC illustrated its functional limitations and facilitated how participants' developed trust in information provided by the technology. For participants, trust was described as a function of understanding the purpose of the technology. Jacob (age 84) described his trust in the system as "I would trust the technology to do what it's supposed to do." Repeated experiences of using the technology not only reinforced participants' understanding of the strengths and limitations of the system but also how much and when they should rely on the information.

\section{Theme 3 'I'm checking everything': Integrating technology into visual scanning patterns}

Participants described their reversing behaviours as routine actions performed in specific sequences unique to each individual (e.g., turning their head, then looking at side mirrors, then looking at the rear mirror, etc.). Integrating use of the RVC into these sequences of scanning actions was more likely to be triggered when the reversing maneuver was complex.

They described the RVC as a useful tool that helped them to assess hazards in the driving environment. For example, Esther perceived her RVC as the final part of the coordinated actions she went through,

such as first physically scanning her surroundings by turning her body and head, and then focusing her attention on the information displayed on her RVC: "I'd get the car about half out lof parking spot]... I'm checking everything, absolutely everything.... and then the camera is very important here because I want to make sure nothing is in that camera range." (Esther, age 76)

Randal (age 76) described how using an RVC in conjunction with other parking assistance systems interrupted his established sequence of scanning actions: "I'm using the side mirror... if it [proximity sensor] goes from beep.... Beep... beep, beep, beep, beep, you know, I'll take a little closer look [at RVC display]". Joshua also described how the information from the RVC might supersede information from other ADAS in decision making during a reversing maneuver. "So the thing is there are multiple things -- multiple pieces of information. Just because now if I were backing and saw with the rear view camera that I still had space, and for some reason the proximity sensor went off, I might make a decision to override that." (Joshua, age 69)

Once participants felt they understood how the RVC augmented information they received from other sources (i.e., mirrors), they reported being able to use the technology as needed.

\section{Theme 4 'Buddy in the car': Technology assists, but does not replace, good driving skills}

The final theme describes the goal of technology adoption by older drivers. Participants described the outcome of learning to use RVCs in their everyday driving. An RVC in the car was seen as an advantageous and convenient addition to the vehicle, but not a replacement for existing driving skills. Participants used terms such as "supplement", "aide", "extra", or "assist" when describing their use of this technology during reversing manoeuvres. Once she was used to using the technology, Esther (age 76) considered her RVC as "a buddy in the car" Jacob (age 84) described his expectations of technology function as "...trust[ing] the technology to do what it is supposed to do."

Using the RVC appropriately was seen as making the reversing manoeuver easier and more efficient by reducing stress associated with the task and increasing participants' confidence. Participants indicated that their ability to effectively use the RVC was reflective of the ease with which they could perform the reversing maneuver, as Nigel (age 81) described: "[the RVC] lubricates the process [of reversing]." Similarly, Edmund (age 77) noted his RVC helped with "speeding things up a little," or "making it a bit simpler." Use of an RVC also made participants feel safer when reversing, given their perceived improved precision when 
performing reversing manoeuvres. For example, Evelyn described how incorporating all the available information made her feel safe: "The way things happen, the way people move in a parking lot and the way things happen so quickly...its one extra thing that I have that helps me to feel really safe. So I'm not letting the other things go, I'm incorporating all of these modalities to help me to drive safely." (Evelyn, age 72)

For some participants, using an ADAS system was seen as an implicit requirement to be expected with the purchase of a new vehicle. Nigel (age, 81) described how he saw the introduction of an RVC into his new car and subsequent changes to his reversing behaviour as "just part of the evolution."

\section{Discussion}

The proliferation ADAS across levels 0 to 2 (i.e., no automation, driver assistance, and partial automation) $)^{15}$ in today's automobile marketplace provides a unique opportunity to explore how older adults learn to drive with these types of systems ${ }^{28}$. Older drivers in the current study described how RVCs enabled their performance of complex reversing manoeuvres more easily, effectively, and safely. This study identified a three-stage learning process with an outcome of using the device as an assist. Through this process, participants began to understand the value of the system with identifying key information in the driving environment. The sequence in which older drivers learned to use RVCs is an important finding, given the current gap in evidence with describing how older adults adapt and integrate new technology into their existing driving habits and routes. The process involves first becoming acquainted with the purpose and function of the RVC, then experimenting with the technology to understand its strengths and limitations. The technology is then integrated into existing reversing-related behaviours. Several factors across identified themes influence this learning process, which includes initial experiences with an RVC; levels of complexity in the driving environment; and a linear progression through distinct stages of learning.

\section{Initial experiences shape how older drivers use RVCs}

The first introduction to the RVCs in their new vehicles was found to be a critical point when learning to use the technology began. Although all participants had a general awareness of RVCs prior to vehicle purchase, most had not considered how the device is actually used or how it might change their reversing behaviours. Initial experiences with this technology were pivotal in establishing participants' understanding of the purpose and function of the technology. Study findings also support others ${ }^{16,25}$ that suggest technology orientation and initial interactions with a

device are a critical point when the value of the technology is established. To ensure older drivers have an accurate understanding of technology capacity, it is imperative that they receive an early and thorough orientation to device operation.

To establish new habits, participants needed to trust the information provided in the RVC display. During their first attempts of using the RVC, they learned the types of information the technology provided. These experiences in turn informed the level of trust participants placed in the technology. Trösterer and colleagues ${ }^{16}$ suggested drivers who learned to use parking assistance systems in their own vehicles can experience fluctuations in their level of trust, within the initial 60 days of using a technology $y^{16}$. Moreover, Souders and Charness ${ }^{6}$ indicated that positive experiences are critical for older drivers when learning to use technology. Perceptions of how a technology works should match one's actual experiences with using a device $^{6}$. Our study confirmed these findings, and, further suggested that negative interactions are also important during the learning process. However, caution is warranted when considering negative experiences as a learning strategy due to the potential danger posed to drivers as well as other road users. Alternative learning strategies, such as simulator training or in-class education, may need to be considered for educating older drivers on the functionality and limitations of technology and promoting the development of trust in ADAS.

Learning to use technology is a process for users of any age. For older drivers, the process of learning to use ADAS begins with an initial orientation to vehicle technologies. Hickman, Rogers, and Fisk $^{29}$ suggest such training on technology use should 'guide' rather than 'tell' older users what to do. Training approaches that provide prescriptive, step-by-step instructions are less effective than those that are more flexible and allow older adults to explore the technology using hands-on learning ${ }^{29}$. Exploring the effectiveness of handson learning approaches is important to promote generalizability across technologies that share similar operational characteristics ${ }^{30}$. Training strategies tailored to this population may reduce the need for older adults to seek out their own resources, thus expediting the learning process.

\section{Environmental factors influence learning to use RVCs}

The physical design of ADAS has been recognized as critical to usability ${ }^{31}$. Participants considered the design of their system to be 'intuitive.' An optimal fit between the age and health-related abilities of the older driver and the microenvironment inside the vehicle (e.g., understanding information in the RVC display) can also support behavioural adaptation ${ }^{31-33}$. When ADAS design is easy to learn and integrate within existing hab- 
its, there is a higher probability that older drivers will use this technology safely.

Environments that facilitated the learning process also extended to perceived access to supports and learning resources, which is captured in the CTAM construct of facilitating conditions ${ }^{22}$. Participants explored the functional limits of the technology in their driveways and also with friends or family. They accessed vehicle manuals and other resources to interpret information provided by the RVC during these experiments. In their survey $(n=2990$, age $(\min , \max )=65$, 79), Eby and colleagues ${ }^{20}$ found that eighteen percent of older adults with RVCs learned about the technology from salespeople at automotive dealerships, which was similar to participants in the current study. The quality and quantity of information provided to drivers from this source have been found to vary ${ }^{21}$. Vehicle manufacturers have been urged to consider developing ADASrelated training materials that educate all drivers, particularly those that are older ${ }^{34}$.

Participants indicated that looking at the RVC display was most often prompted by a gap in visual information about the driving environment. Some have raised concerns about negative repercussions on road safety if older adults rely too heavily on $\mathrm{ADAS}^{28}$. In contrast, study participants emphasized that they did not use the RVC exclusively or as a replacement for obtaining information from other sources. Research suggests older drivers are aware of the need to divide their attention across various strategies (e.g., mirror use and shoulder checks) ${ }^{17,18}$. Appropriate integration of information across sources is dependent on older drivers' ability to use the technology according to its intended purpose. Older drivers can benefit from ADAS, but safe adoption is critical given their already high risk of collision ${ }^{35}$. Simões and Pereira use the term 'behavioural adaptation' in relation to how older drivers adjust their routines and habits to accommodate new technologies in their vehicles ${ }^{36}$. They argued that successful behavioural adaptation is difficult for older drivers. However, findings of the current study challenge this assertion by proposing that successful behavioural adaptation can occur but through a process of successive stages.

\section{Learning to use an RVCs in older adulthood in- volves a series of key steps}

For the older drivers in this study use of the RVCs occurred over time as they began to understand how the technology worked in various situations. The learning process had distinct steps or stages which have not been captured in theoretical models used to explain user experiences with ADAS. The CTAM is helpful to understand factors that contribute to older drivers' initial acceptance of in-vehicle technologies but it lacks a temporal aspect. The CTAM predominantly focuses on two key time points in relation to ADAS: (1) technology acceptability, as it relates to the intention to use technology (i.e., prior to actual use of ADAS), and (2) technology adoption at time of first use (i.e., initial impressions of ADAS after use $)^{22}$. For example, in their study on the acceptance of navigation systems among older drivers, Bryden and colleagues based their findings on a single interaction with a navigation system, meaning participants were not tracked across time ${ }^{37}$. A recent systematic review on acceptance and use of technology designed to support aging-in-place has identified a dearth of studies examining older adults' ongoing use of a technology after their initial interactions ${ }^{38}$.

Researchers suggest the duration of time needed to integrate new ADAS into existing routines and acceptance of the technology depends on multiple factors that include but are not limited to: the complexity of the technology (e.g., how easy it is to use $)^{36}$, driver characteristics (e.g., age, gender, and driving experiences) ${ }^{36,39}$, and frequency of use $^{36}$. As such, most drivers cannot be expected to use the technology or respond to information from RVCs appropriately when they first purchase the vehicle. For older drivers, changes in physical and cognitive abilities over time may also require them to re-learn how to use their RVCs in response to potential changes in driving abilities.

\section{Limitations}

Participants in the current study were recruited using existing databases of those who had taken part in earlier driving-related research. Thus, participants in the current study might have a predisposed interest in driving research and, as such, their views may not be reflective of the older demographic of the general driving population. This study was also not able to assess the effects of health status and gender on technology adoption due to its small sample size. Changes in physical and cognitive health due to age and medical conditions may result in different experiences when using this technology ${ }^{40}$. The sample also consisted of a couple who shared the same vehicle, which may have influenced how they learned to use the RVC. In fact, older couples may learn to use ADAS more successfully when working together ${ }^{24}$.

Our study sample represented a subset of the population for whom learning and adopting technology are seen as positive, given their high level of education. However, a recent study has shown that the difference between proportions of older adults with high school education or less and graduate degrees, that own vehicles with reversing systems, is only $13 \%$ indicating that a sample with lower levels of education would still have access to this technolo$\mathrm{gy}^{20}$. Although household income was not captured in this study, access to economic resources suggests 
higher technology adoption in older adults ${ }^{41}$. Older adults that have a household income of $\$ 100,000$ are twice as likely to own vehicles with reversing systems, compared to those with a household income between $\$ 20,000$ and $\$ 49,000^{20}$.

The diversity in technology packages available from different automotive manufacturers reduces the potential to compare users' experiences of the same types of ADAS. Nonetheless, participants' ownership of vehicles equipped with ADAS and their aptitude for self-directed learning made it easier for them to reflect on their experiences learning to use their RVCs. The learning process described in the current study is related to technologies that do not take over vehicle operation (i.e., level 1 automation ${ }^{15}$ ). For partially autonomous technologies (i.e., level $2^{15}$ ) that do take over vehicle operation, it is important to understand how older drivers learn to respond to the transitions between manual and automatic vehicle operation. Study findings suggest that a staged approach to learning needs to be considered to optimize older adults' appropriate use of more complex technologies.

\section{Recommendations}

For older drivers, access to training early in the RVC adoption process should focus on emphasizing the purpose, operation, and limitations of the system in question. Training and education for optimal use of RVCs, and other ADAS, should extend beyond initial interactions with the technology. Building trust through such training is important, which can be achieved by using the system in situations of varying complexity. Future research should consider tracking older drivers' efficiency and precision in reversing maneuvers across the learning process. Studies should also examine the learning process across levels of ADAS automation with older drivers that have varying levels of health and technology experience. The effects of gender and socioeconomic backgrounds on learning to use ADAS should be explored. Variations in ADAS design and function across vehicle manufacturers is also an important factor to consider when examining the learning process and subsequent technology use. LongROAD, a large longitudinal study in the United States, is currently tracking older drivers' use of ADAS alongside other health and sociodemographic variables. This study will be one of the first to explore the impact of such technologies on our aging population over time.

\section{Conclusion}

Findings from the current study highlight the importance of considering older drivers' experiences of learning to use RVCs. Understanding the perspectives of older drivers when it comes to learning to use ADAS is critical to inform improvements in technology design by designers of vehicle technologies. Their perspectives should also be considered by those responsible for training and educating consumers on how to use these technologies safely and appropriately. Older drivers' use of vehicle technology has the potential to improve their behind-the-wheel performance, and even extend their safe driving years.

\section{References}

1. National Highway Traffic Safety Administration (NHTSA). Not-in-traffic surveillance: Fatality and injury statistics in nontraffic crashes, 2008-2011 (DOT HS 811 813). Washington, DC: National Highway Traffic Safety Administration; 2014a

2. Stutts JC, Steward R, Martell C. Cognitive test performance and crash risk in an older driver population. Accident Analysis and Prevention 1998; 30(3): 337-346

3. Douissembekov E, Gabaude C, Rogé J, Navarro J, Michael GA. Parking and manoeuvring among older drivers: A survey investigating special needs and difficulties. Transportation Research Part F: Psychology and Behaviour 2014; 26: 238-245; https:// doi.org/10.1016/j.trf.2014.07.011

4. Karali S, Gyi DE, Mansfield NJ. Driving a better driving experience: A questionnaire survey of older compared with younger drivers. Ergonomics 2017; 60(4): 533-540; https://doi.org/10.1080/00140139. 2016.1182648

5. Eby DW, Molnar LJ, Zhang L, St. Louis R, Zanier N, Kostyniuk LP. Keeping older adults driving safely: A research synthesis of advanced in-vehicle technologies. Washington, DC: AAA Foundation for
Traffic Safety; 2015

6. Souders DJ, Charness N. Travel safety and technology adoption by elderly populations. In Proceedings of the Florida Automated Vehicles Summit, 1516 December; 2014

7. Kidd DG, Brethwaite A. Visibility of children behind 2010-2013 model year passenger vehicles using glances, mirrors, and backup cameras and parking sensors. Accident Analysis and Prevention 2014; 66: 158-167; https://doi.org/10.1016/j.aap.2014.01.006

8. Hurwitz DS, Pradhan A, Fisher DL, Knodler MA, Muttart JW, Menon R, Meissner U. Backing collisions: A study of drivers' eye and backing behaviour using combined rear-view camera and sensor systems. Injury Prevention 2010; 16: 79-84; https:// doi.org/10.1136/ip.2009.021535

9. Keall MD, Fildes B, Newstead S. Real-world evaluation of the effectiveness of reversing camera and parking sensor technologies in preventing backover pedestrian injuries. Accident Analysis and Prevention 2017; 99: 39-43; https://doi.org/10.1016/j. aap.2016.11.007

10. Kidd DG, McCartt AT. Differences in glance behavior between drivers using a rearview camera, parking sensor system, both technologies, or no 
technology during low-speed parking manoeuvres. Accident Analysis and Prevention 2016; 87: 92-101; https://doi.org/10.1016/j.aap.2015.11.030

11. Cicchino JB. Effects of rearveiw cameras and rear parking sensors on police-reported backing crashes. Traffic Injury Prevention 2017; 18: 859-865; https://doi.org/10.1080/15389588.2017.1317758

12. Cicchino JB. Real-world effects of General Motors rear automatic braking, rear vision camera, and rear parking assist systems. Arlington, VA: Insurance Institute for Highway Safety; 2018

13. National Highway Traffic Safety Administration (NHTSA). Federal motor vehicle safety standards; Rear visibility (Federal Register, 79(66), 49 CFR Part 571. Docket no. NHTSA-2010-0162). Washington, DC: National Highway Traffic Safety Administration; 2014b

14. Transport Canada. 2014 Canadian motor vehicle traffic collision statistics. Catalogue No. T45-3EPDF; 2016

15. National Highway Traffic Safety Administration (NHTSA). Federal Automated Vehicles Policy. Washington, DC: National Highway Traffic Safety Administration; 2016

16. Trösterer S, Wurhofer D, Rödel C, Tscheligi M. Using a parking assist system over time: Insights on acceptance and experiences. In Proceedings of the 6th International Conference on Automotive User Interfaces and Interactive Vehicular Applications, 17-19 September, Seattle, WA; 2014; https://doi. org/10.1145/2667317.2667327

17. Jenness JW, Lerner ND, Mazor S, Osberg JS, Tefft BC. Use of advanced in-vehicle technology by young and old early adopters. Report No. DOT HS 810 828. Washington, DC: National Highway Traffic Safety Administration; 2007

18. Mueller A, Sangrar R, Vrkljan B. Rearview camera system use among older drivers: A naturalistic observation study. Transportation Research Part F: Traffic Psychology and Behaviour. 2017 [In Press]; https://doi.org/10.1016/j.trf.2017.06.014

19. McDonald AB, McGehee DV, Chrysler ST, Askelson NM, Angell LS, \& Seppelt BD. National survey identifying gaps in consumer knowledge of advanced vehicle safety systems. Transportation Research Record: Journal of the Transportation Research Board, No. 2559, Transportation Research Board, Washington, D.C., 2016, pp. 1-6. https:// doi.org/10.3141/2559-01

20. Eby D. Prevalence, attitudes, and knowledge of in-vehicle technologies and vehicle adaptations among older drivers. Accident Analysis and Prevention 2018; 113: 54-62; https://doi.org/10.1016/j. aap.2018.01.022

21. Abraham $H$, McAnulty $H$, Mehler B, \& Reimer B. Case study of today's automotive dealerships: Introduction and delivery of advanced driver assistance systems. Transportation Research Record: Journal of the Transportation Research Board No. 2660 2017; 7-14. https://doi.org/10.3141/2660-02

22. Osswald S, Wurhofer D, Trösterer S, Beck E, Tscheligi M. Predicting information technology usage in the car: Towards a car technology acceptance model. In proceedings of the 4 th International
Conference on Automotive User Interfaces and Interactive Vehicular Applications. ACM; 2012; pp5158; https://doi.org/10.1145/2390256.2390264

23. Venkatesh V, Morris MG, Davis GB, Davis GB. User acceptance of information technology: Toward a unified view. MIS Quarterly 2003; 27(3): 425-478; https://www.jstor.org/stable/30036540; retrieved May 29, 2018

24. Vrkljan BH, Polgar MJ. Driving, navigation, and vehicular technology: Experiences of older drivers and their co-pilots. Traffic Injury Prevention 2007; 8(4): 403-410; https://doi. org/10.1080/15389580701576423

25. Rahman MM, Lesch MF, Horrey WJ, \& Strawderman L. Assessing the utility of TAM, TBP, and UTAUT for advanced driver assistance systems. Accident Analysis and Prevention 2017; 108: 361373; https://doi.org/10.1016/j.aap.2017.09.011

26. Reimer B. Driver assistance systems and the transition to automated vehicles: A path to increase older adult safety and mobility? Public Policy \& Aging Report 2014; 24: 27-31. https://doi.org/10.1093/ppar/prt006

27. Braun V, Clarke V. Using thematic analysis in psychology. Qualitative Research in Psychology 2006; 3: 77101; https://doi.org/10.1191/1478088706qp063oa

28. Gish J, Vrkljan B, Grenier A, Van Miltenburg B. Driving with advanced vehicle technology: A qualitative investigation of older drivers' perceptions and motivations for use. Accident, Analysis and Prevention 2016; 1-16; https://doi.org/10.1016/j. aap.2016.06.027

29. Hickman JM, Rogers WA, Fisk AD. Training older adults to use new technology. Journals of Gerontology 2007; 62(B): 77-84; doi:10.1093/geronb/62. special_issue_1.77

30. Lee C, Mehler B, Reimer B, Coughlin JF. User perceptions toward in-vehicle technologies: Relationships to age, health, preconceptions, and hands-on experience. International Journal of Human-Computer Interactions 2015; 31: 667-681; https://doi.org /10.1080/10447318.2015.1070545

31. Ball KK, Wahl H. Driving in old age: Use of technology to promote independence. Gerontechnology 2002; 1(4): 217-219

32. Rakotonirainy A, Steinhardt DA. In-vehicle technology functional requirements for older drivers. In Proceedings of the 1st International Conference on Automotive User Interfaces and Interactive Vehicular Applications, 21-22 September 2009, University of Duisburg-Essen, Essen, Germany

33. Stav W. CarFit: an evaluation of behaviour change and impact. British Journal of Occupational Therapy 2010; 73(12): 589-597; https://doi.org/10.4276/0 30802210X12918167234208

34. Eby DW, Molnar LJ, Zhang L, St. Louis RM, Zanier N, Kostyniuk LP, Stanciu S. Use, perceptions, and benefits of automotive technologies among aging drivers. Injury Epidemiology 2016; 3(28): 1-20; https://doi.org/10.1186/s40621-016-0093-4

35. Coughlin CF, Reimer B. New demands from an older population: An integrated approach to defining the future of older driver safety. In Proceedings of the Society of Automotive Engineers Convergence Conference. Convergence Transportation Electron- 
ics Association and SAE International; 2006

36. Simões A, Pereira M. Older drivers and new invehicle technologies: Adaptation and long-term effects. In M. Kurosu (Ed.) Human Centered Design. Berlin: Springer-Verlag; 2009; pp 552-561

37. Bryden KJ, Charlton JL, Oxely JA, Lowndes GJ. Acceptance of navigation systems by older drivers. Gerontechnology 2014; 13(1): 21-28; https://doi. org/10.4017/gt.2014.13.1.011.00

38. Peek STM, Wouters EJM, van Hoof J, Luijkx KG, Boeije HR, Vrijoef HJM. Factors influencing acceptance of technology for aging in place: A systematic review. International Journal of Medical Informatics 2014; 83:235-248; https://doi.org/10.1016/j.ijmedinf.2014.01.004
39. Son J, Park M, \& Park BB. The effect of age, gender and roadway environment on the acceptance and effectiveness of advanced driver assistance systems. Transportation Research Part F 2015; 31: 12-14. https://doi.org/10.1016/j.trf.2015.03.009

40. Baldwin CL. Designing in-vehicle technologies for older drivers: Application of sensory-cognitive interaction theory. Theoretical Issues in Ergonomics Science 2002; 3(4): 307-329; https://doi. org/10.1080/1463922021000009029

41. Wang A, Redington L, Steinmetz V, Lindeman D. The ADOPT model: Accelerating diffusion of proven technologies to older adults. Ageing Int 2010; https://doi.org/10.1007/s12126-010-9072-1 